\title{
Immunological modulation and evasion by helminth parasites in human populations
}

\author{
Rick M. Maizels, Don A. P. Bundy, Murray E. Selkirk, Deborah F. Smith \\ \& Roy M. Anderson
}

\begin{abstract}
Helminth parasites are highly prevalent in human communities in developing countries. In an endemic area an infected individual may harbour parasitic worms for most of his or her life, and the ability of these infections to survive immunological attack has long been a puzzle. But new techniques are starting to expose the diverse mechanisms by which these agents modulate or evade their hosts' defences, creating a dynamic interaction between the human immune system and the parasite population.
\end{abstract}

SEVENTY per cent of the global population lives in the developing world, where helminths are one of the commonest types of infection and one third of the population harbours intestinal helminths such as Ascaris lumbricoides and Trichuris trichiura ${ }^{1}$. A child born in an area where intestinal nematodes, schistosome flukes or filarial worms are endemic can expect to harbour worms for most of his or her life owing to repeated exposure to infection and an inability to develop protective immunity.

Infectious agents can be divided into microparasites and macroparasites ${ }^{2}$. The former include viruses, bacteria and protozoa and have direct reproduction within the host, often at high rates. Macroparasites include the helminths and do not multiply within the definitive host, but reproduce sexually to produce transmission stages that egress through faeces or urine, or via a biting arthropod vector. Most microparasitic infections are acute and short-lived and, following recovery, immunity may be protective and even lifelong. In contrast, macroparasites induce long-lasting, chronic infections in which individual organisms persist over long periods.

The ability of helminths to survive in the host for protracted periods despite abundant evidence of immune recognition and attack remains a puzzle of both practical and fundamental significance. Helminth species have complex genomes and elaborate developmental cycles, however, and it would be surprising if they had not evolved mechanisms to combat the host's defence. The growing integration between laboratory and field studies indicates that there is a wide array of mechanisms by which the parasite evades or modulates host immunological attack. A key facet of parasite persistence appears to be enhancement of downregulatory arms of the immune system to induce tolerance or anergy in the face of repeated infection. This review examines recent epidemiological, immunological, molecular and theoretical studies of the factors that result in persistent infection. Understanding these factors will be central to the development of effective vaccines and better drugs, as well as shedding light on how the existence of these parasites has shaped the evolution of the immune system.

\section{Biological features of helminth infections}

In humans, the most striking features of parasitic helminths are long-term persistence within the host ${ }^{3}$, the ability to elicit protective immunity only after many years or even decades of exposure ${ }^{4}$, complex developmental cycles often involving stagespecific antigens ${ }^{5}$, aggregated distribution in human communities where a minority of people harbour the majority of worms ${ }^{6}$, and the occurrence of individuals predisposed to heavy infection ${ }^{7,8}$. Helminths cause morbidity rather than mortality, with disease severity typically related to worm burden. The persistent nature of infection, with progressive accumulation of par- asites, can induce chronic sequelae such as hepatosplenic disease induced by Schistosoma manson $i^{9}$, lymphoedema and elephantiasis induced by lymphatic filariasis and blindness caused by Onchocerca volvulus ${ }^{1}$. Long-term infection, particularly if associated with poor nutrition, can lead to impaired physical and cognitive development in children with high worm loads ${ }^{10}$. Disease may itself result from host immunological responses mediating damage to sites at which parasites have accumulated ${ }^{9,11}$

Microparasites often ensure their persistence in human communities by antigenic variation and diversity. Although helminths maintain genetic variability through sexual reproduction (evidenced by the emergence of drug-resistant strains), their generation of new antigen variants is unlikely to be rapid enough because the generation time of the parasite is not much less than that of the host. Genetic heterogeneity within the parasite population may be in part maintained by genetic variation in the human community, where a few hosts predisposed to heavy infection provide a refuge in which parasites can survive and reproduce against a background of deficient immunological defences. Information on genetic heterogeneity in helminth populations, however, remains limited ${ }^{12}$.

Transmission between hosts is an uncertain process and, as a result, helminths tend to produce very large numbers of transmission stages (a mature female Ascaris can produce 200,000 eggs per day). However, life-cycle strategies vary between species and, as in most organisms, life expectancy of the mature worm, rates of egg or larval production and transmission success (the magnitude of the basic reproductive rate, $R_{0}$ ) are correlated. Long-lived filarial species produce offspring at a lower rate than short-lived intestinal nematodes. Following curative chemotherapy, rates of reinfection are low with filarial worms such as $O$. volvulus (life expectancy $8-10 \mathrm{yr}$ ), moderate for schistosome flukes (3-5 yr) and very rapid for intestinal nematodes such as A. lumbricoides $(1 \mathrm{yr})^{13}$. Life history strategy and transmission success therefore determine the ideal interval between rounds of mass chemotherapy designed to suppress infection to very low levels ${ }^{14}$.

\section{Epidemiological patterns}

The epidemiological picture of persistent helminth infection is set by the long parasite lifespan, and by repeated reinfection throughout the host's own lifetime. Estimates of life expectancy of endoparasites residing in the gut, mesenteric veins or the lymphatic system are crude, and depend on studies of the rate of decline of prevalence and intensity of infection in groups of people who cease to be exposed to infection (in the absence of chemotherapy) (Fig. $1 a$ and $b$ ). The observed patterns of decay can be translated into a measure of parasite lifespan on the basis of the frequency distribution of parasite numbers per person ${ }^{15}$, 
which is typically well described by the negative binomial probability distribution, irrespective of the community studied (Fig. 1d). The negative binomial model describes aggregated or clumped distributions (where the variance in worm numbers is greater than the mean) in which most people harbour few worms and a few hosts hold a large number of parasites. For many helminths, a very tight relationship exists between the fraction infected (prevalence) and average worm load (intensity) (Fig. $1 c)^{16}$ and measures of the degree of aggregation (measured inversely by the parameter $k$ ) are remarkably constant for a given infection over very diverse populations. Aggregation becomes less marked as people age, reflecting either a slow build-up of specific immunity ${ }^{4}$ or variation in susceptibility to infection over time $^{13}$. Taking studies on both infection rate decay and parasite distribution into account, the estimates of life expectancies listed in Table 1 suggest long-term persistence in the host. Surprisingly, persistence in habitats such as the blood or lymphatic system appears longer than in the gut. The long-term survival of tissuedwelling schistosomes and filarial parasites, despite their most intimate contact with the immune system, suggests that they have evolved particularly effective mechanisms of immune evasion or modulation.

Repeated infection of human populations is revealed by crosssectional studies that chart changes in worm loads across each age class, and by longitudinal cohort studies in which rates of reinfection following chemotherapy are monitored (Fig. 2a). In the absence of acquired immunity or heterogeneity in exposure, the pattern of change is described by an immigration-death model in which the average intensity rises with age until reaching an equilibrium at the point at which the per capita rate of host infection, $\Lambda$, is balanced by the net mortality of the mature parasite, $\mu$ (ref. 3). Rates of reinfection reflect the magnitude of the basic reproductive rate, $R_{0}$, a measure of the average number of offspring produced by one female worm (in the case of dioecious species) that attains reproductive maturity. Reinfection is much faster for Ascaris (mean burdens of which can return to precontrol levels within one year of treatment) than for $S$. mansoni $i^{4.17}$ or filarial worms ${ }^{18}$. All age classes reacquire infection following treatment, but in schistosomiasis ${ }^{17,19}$ older age classes reacquire infection at slower rates than younger groups. This reflects elements both of age-related exposure patterns, and of acquired immunity (integrating the experience of past infection accumulated as the host ages in an environment where repeated exposure takes place). Water contact patterns in schistosomeendemic areas are age-dependent ${ }^{20}$, as are geophagic habits favouring geohelminth transmission (reflected by the presence of silica in children's faeces) $)^{21}$. As a result, the change in mean worm burden with age for many helminths follows a convex curve in which the age of peak intensity depends on various factors, including the life expectancy of the parasite (in younger age classes of children for short-lived intestinal nematodes, and in teenagers or young adults for schistosomes and filarial worms, respectively), the intensity of transmission (earlier in high transmission areas and vice versa), and on behavioural factors (agerelated exposure to infection). Interestingly, the pattern of change with age tends to be more peaked or convex in hightransmission areas than in low ones, supporting the hypothesis that acquired immunity develops slowly in a manner related to accumulated past exposure to infection (Fig. $2 b)^{22,23}$.

\section{Evidence for immune-mediated resistance}

Three concepts of importance in immunity to helminth infections
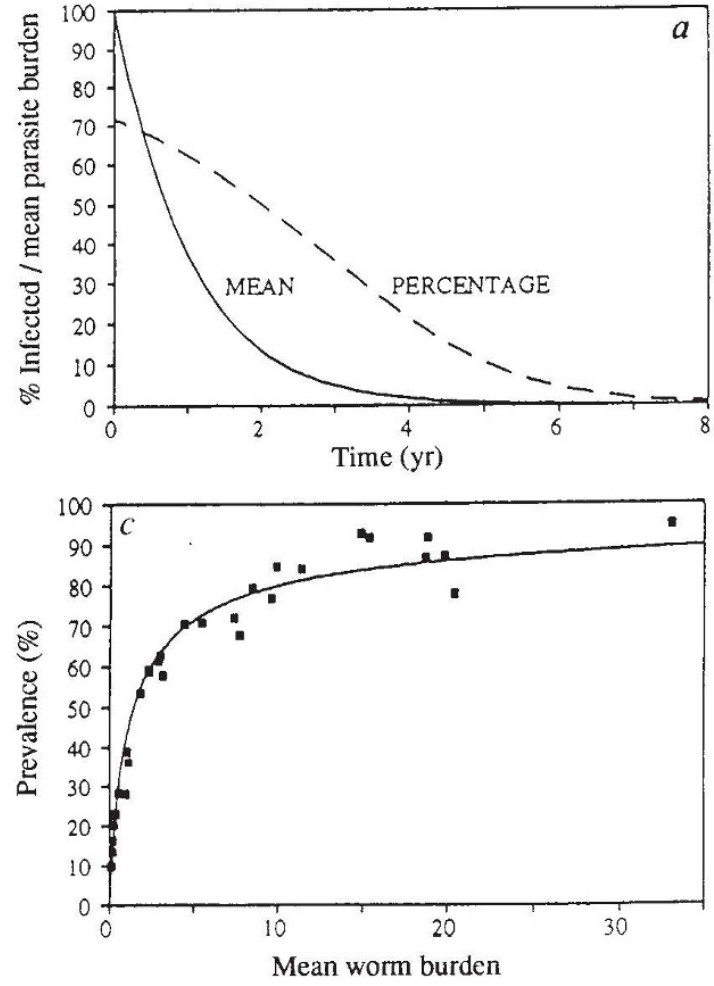

FIG. 1 a, The predicted pattern of decay over time in the prevalence and intensity of infection with a parasite, the distribution of which within the host population is aggregated or overdispersed and whose exposure to infection ceases at time $t=0 . b$, The decay in prevalence of Wuchereria bancrofti infection within a sample of people no longer exposed to infection. Crosses are observed values ${ }^{140}$, and the solid line is the prediction of a simple model of decay ${ }^{13}$. c, The nonlinear relationship between the prevalence of infection (\% infected) and the mean intensity of infection (mean worm burden) for Ascaris lumbricoides. The solid
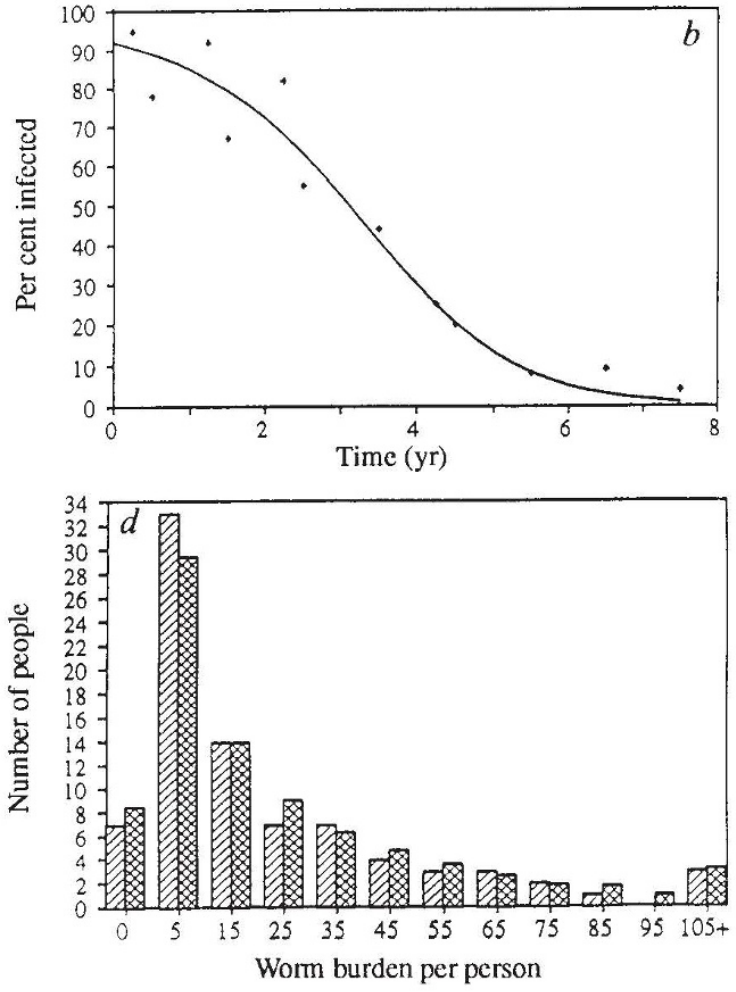

line is the relationship predicted by the negative binomial probability model (to describe aggregated distributions) and the squares denote observed values from a wide variety of studies in different Asian and African countries ${ }^{16}$. d, The frequency distribution of the number of Ancylostoma duodenale per person in a study in India (hatched) compared with the expected values (cross-hatched) of the best-fit negative binomial probability model (mean, 24.54 worms per person; $k=0.618$ (ref. 7). 
TABLE 1 Epidemiological characteristics of some of the principal helminth infections in humans*

Basic parameters of adult helminth parasites in the human host

\begin{tabular}{ll}
\multicolumn{1}{c}{ Parasite } & $\begin{array}{l}\text { Common name of } \\
\text { parasite (disease) }\end{array}$ \\
Enterobius vermicularis & Pinworm \\
Trichuris trichiura & Whipworm \\
Ascaris lumbricoides & Roundworm \\
Necator americanus & Hookworm \\
Ancylostoma duodenale & Hookworm \\
Schistosoma mansoni & Blood fluke (Bitharzia) \\
Schistosoma haematobium & Bladder fluke \\
Wuchereria bancrofti & Filarial worm \\
Onchocerca volvulus & (River blindness)
\end{tabular}

Rates of egg production by mature parasites in the human host

\begin{tabular}{|c|c|c|c|c|c|}
\hline & $\begin{array}{l}\text { Rate of egg } \\
\text { production }\end{array}$ & & Parasite & Mode of entry & $\begin{array}{l}\text { Maturation } \\
\text { delay (d) }\end{array}$ \\
\hline Parasite & $\begin{array}{l}\text { (per female } \\
\text { per day) }\end{array}$ & $\begin{array}{c}\text { Role of egg in } \\
\text { transmission of disease }\end{array}$ & $\begin{array}{l}\text { Schistosoma haematobium } \\
\text { Schistosoma mansoni }\end{array}$ & $\begin{array}{l}\text { Percutaneous } \\
\text { Percutaneous }\end{array}$ & $\begin{array}{l}21-28 \\
25-30\end{array}$ \\
\hline $\begin{array}{l}\text { Ascaris } \\
\text { lumbricoides }\end{array}$ & $>200,000$ & $\begin{array}{l}\text { Embryonates in soil to } \\
\text { become infective egg if } \\
\text { ingested by mouth }\end{array}$ & $\begin{array}{l}\text { Ancylostoma duodenale } \\
\text { Ascaris lumbricoides } \\
\text { Trichuris trichiura }\end{array}$ & $\begin{array}{l}\text { Percutaneous } \\
\text { Oral } \\
\text { Oral }\end{array}$ & $\begin{array}{l}28-50 \\
50-80 \\
50-84\end{array}$ \\
\hline $\begin{array}{l}\text { Ancylostoma } \\
\text { duodenale }\end{array}$ & $10,000-20,000$ & $\begin{array}{l}\text { Hatches in soil to } \\
\text { produce skin-penetrating } \\
\text { infective larva (L3) }\end{array}$ & \multicolumn{3}{|c|}{ Degree of parasite aggregation in human communities $\S$} \\
\hline $\begin{array}{l}\text { Schistosoma } \\
\text { haematobium }\end{array}$ & $500-3,000$ & $\begin{array}{l}\text { Hatches in water to } \\
\text { release miracidium; this }\end{array}$ & $\begin{array}{l}\text { Parasite } \\
\text { Enterobius vermicularis }\end{array}$ & & $k$ value \\
\hline $\begin{array}{l}\text { Schistosoma } \\
\text { mansoni }\end{array}$ & $100-300$ & $\begin{array}{l}\text { invades snail } \\
\text { intermediate host and } \\
\text { reproduces to yield } \\
>1,000 \text { aquatic } \\
\text { cercariae able to } \\
\text { penetrate human skin }\end{array}$ & $\begin{array}{l}\text { Trichuris trichiura } \\
\text { Ascaris lumbricoides } \\
\text { Necator americanus } \\
\text { Schistosoma mansoni } \\
\text { Wuchereria bancrofti }\end{array}$ & & $\begin{array}{r}0.2-0.4 \\
0.2-0.9 \\
0.03-0.4 \\
0.03-0.5 \\
0.6-0.7\end{array}$ \\
\hline
\end{tabular}

* See ref. 13 for sources of estimates.

$\uparrow$ Lifespan estimates are rough approximations owing to practical difficulties inherent in estimation. For further details on helminth biology, see refs $131,143$.

$\ddagger$ Female.

$\$$ Measured inversely by parameter $k$ of the negative binomial probability distribution of worm numbers per host (for $k$ values greater than 5 , the distribution tends to the Poisson (random) form).

are age-related acquisition of resistance, concomitant immunity, and predisposition to infection.

- There is strong evidence for age-dependent acquisition of immunity in humans to the major helminth disease of schistosomiasis , $^{47,19,23}$; a similar pattern is seen in human filariasis $^{24,25}$. Exposure is a major determinant of age-related changes in schistosomiasis (which is dependent on water contact), but not in filariasis (which is mosquito-borne). At all ages, specific antibody and cellular responses targeted at parasite antigens abound, with some measures correlating positively with worm burden ${ }^{26}{ }^{28}$ (Fig. 2c) and others with duration of exposure.

- In concomitant immunity, hosts are protected against newly invading larvae while tolerating an established adult worm load. Originally described in experimental infections with schistosomes $^{29}$, cestodes ${ }^{30}$ and nematodes ${ }^{31}$ in rodent hosts, the limited evidence for concomitant immunity in humans must be dissociated from effects due to the natural rate of parasite population turnover and reinfection within a single host ${ }^{17,19,20,25}$, or from pathophysiological sequelae of infection which may change the niche available to later waves of parasites ${ }^{32}$. Concomitant immunity would imply stage-specific expression of antigens by larvial helminths, and/or an ability of adult worms to subvert or counteract those immune effector mechanisms that kill immature forms. In either case, the infective forms appear valid targets for vaccine development on the basis that human immune systems appear able to reduce their rate of establishment, given some considerable experience of past exposure.

- Predisposition to heavy or light infection is an important epidemiological factor, now established for Ascaris, Trichuris,

$\begin{array}{ccll}\begin{array}{c}\text { Average } \\ \text { lifespan } \\ (\mathrm{yr})^{\dagger}\end{array} & \begin{array}{c}\text { Size of } \\ \text { adult } \\ (\mathrm{mm})\end{array} & \begin{array}{l}\text { Location of } \\ \text { adult parasite }\end{array} & \begin{array}{c}\text { Taxon } \\ <1\end{array} \\ 1-2 & 10 & \begin{array}{l}\text { Colon } \\ \text { Caecum }\end{array} & \begin{array}{c}\text { Nematode } \\ \text { Nematode }\end{array} \\ 1-2 & 30 & \text { Small intestine } & \text { Nematode } \\ 2-3 & 200 & \text { Small intestine } & \text { Nematode } \\ 2-3 & 10 & \text { Small intestine } & \text { Nematode } \\ 3-5 & 12 & \text { Mesenteric veins } & \text { Trematode } \\ 3-5 & 20+ & \text { Vesical plexus } & \text { Trematode } \\ 3-5 & 30_{+}^{+} & \text {Lymphatics } & \text { Nematode } \\ 8-10 & 90_{+}^{+} & \text {Subcutaneous } & \text { Nematode }\end{array}$

Average period from arrival in the human host to maturation

Degree of parasite aggregation in human communities $\S$

Enterobius vermicularis

$0.3-0.4$

$03-0.4$

$0.6-0.7$ 
ing upon the host major histocompatibility complex (MHC) genotype ${ }^{41}$. Similar work in animal models suggests that both MHC and non-MHC genes can be critical to the course of infection $^{37,42}$. In human populations, the combination of these variable factors is undoubtedly a major determinant of parasite aggregation and predisposition.

To tease out the factors that control observed patterns of infection within communities, epidemiological study must turn more and more to detailed longitudinal studies of parasitological and immunological changes in individuals within the community. Recent field studies of this type are beginning to identify patterns which provide important clues to what, amongst many measurable responses to parasite antigens, may determine the build up of acquired immunity which acts to reduce the intensity of infection in older individuals. For example, in studies of the gut-dwelling worm T.trichiura, comparison of age-dependent isotype responses and the age-profile of infection intensity in two endemic communities with very different levels of transmission, suggest that parasite-specific secretory $\operatorname{IgA}$ responses best reflect the accumulated past experience of infection, whereas serum IgG isotypes simply correlate positively with current worm burden $^{43,44}$. For the blood-dwelling schistosome flukes in humans (S. mansoni ${ }^{28}$ and $S$. haematobium ${ }^{26}$ ), circulating specific and nonspecific serum IgE correlates both positively with accumulated past experience of infection, and negatively with reinfection rates after drug treatment.

\section{Immune responses and effector mechanisms}

How does specific immunological resistance to helminth parasites operate? Some information can be drawn from epidemiological correlations, but our understanding rests heavily upon animal model systems and in vitro studies (Table 2 ). In dissecting the elaborate web of immune responses mounted to helminth parasites, one must note that, as argued by Mitchell ${ }^{30}$, individual mechanisms rarely operate in isolation in the natural host, and the most efficient expression of host resistance is likely to be effected by a multicomponent response. Helminths have evolved an array of modulations and interference strategies to match the defence systems of their preferred host, and there is considerable functional overlap between independent immune cell types.
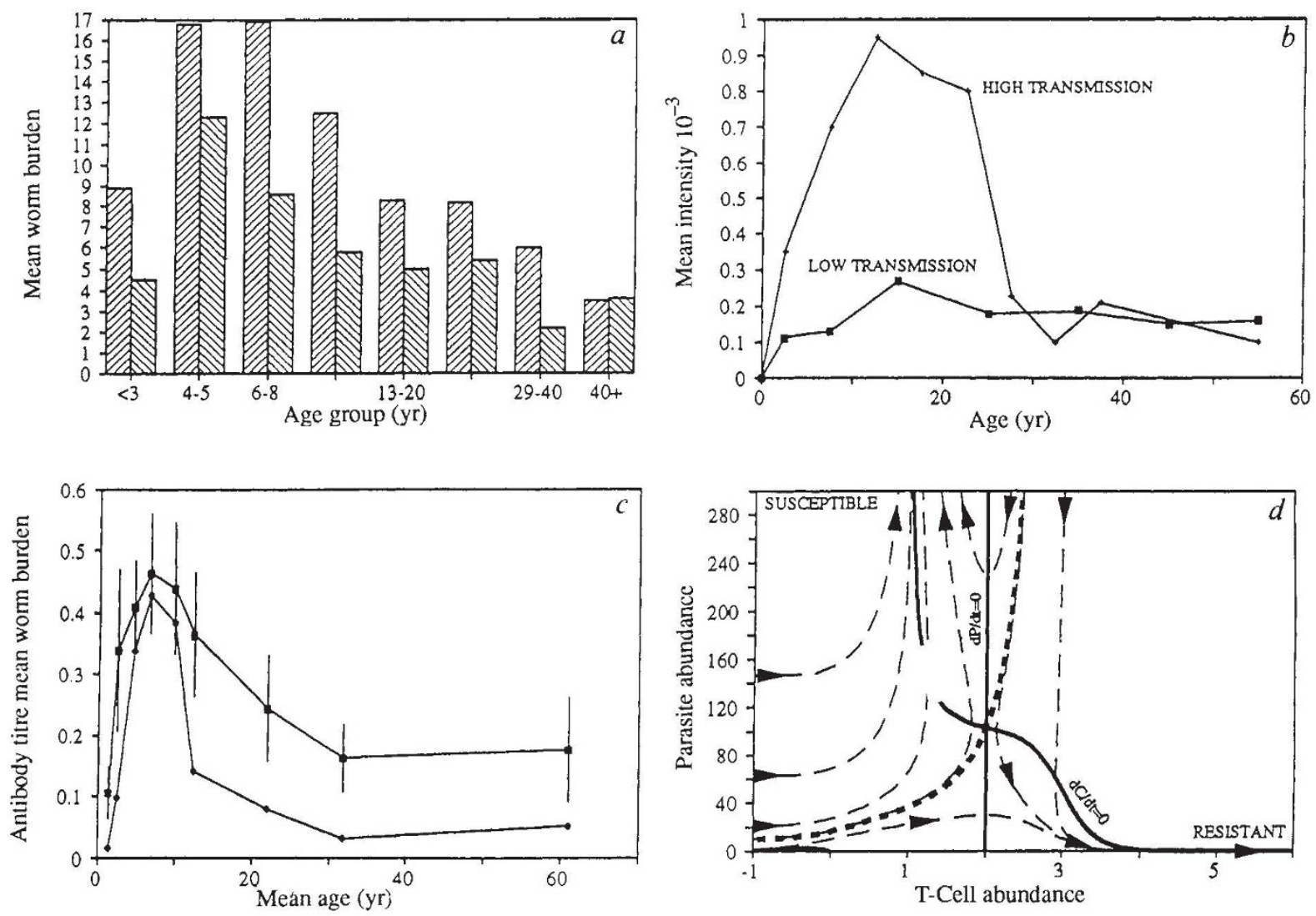

FIG. 2 a, A horizontal age-stratified survey of the intensity of infection (worm burden) with Ascaris lumbricoides in a rural community in India before chemotherapeutic treatment (January 1984; hatched bars) and post-treatment (November 1984; cross-hatched bars) showing rapid rates of reinfection where worm burdens across all age classes approach pre-control levels after 11 months of exposure ${ }^{141} . b$, Horizontal age-stratified surveys of the intensity of infection (eggs per $g$ of faeces) with Schistosoma mansoni in areas of low and high transmission. Note the convex curve in the high-transmission area and the monotonic approach to a plateau with increased age in the low-transmission area. c, Horizontal age-stratified study of the intensity of infection (worm burden) with Trichuris trichiura in a community in St Lucia, West Indies (diamonds) and age-related changes in T. trichiura antigen-specific IgG antibody titres (95\% confidence limits around squares) in sera taken from the study population. Note that antibody titres rise and fall across age classes in a manner related to worm burden ${ }^{142}$. It is unclear

whether humoral responses are protective. $d$, Mathematical models of the dynamic interaction between Th1 lymphocytes and helminth parasite antigens reveal complex patterns of dynamical behaviour where early experience of infection may determine whether the host acquires resistance or remains susceptible as a result of immunological unresponsiveness generated by suppressed Th1 cell abundance. The graph shows a phase plane of the relationships between helminth parasite abundance $(P)$ and Th1 cell abundance $(C)$. The solid lines represent isoclines $(\mathrm{d} P / \mathrm{d} t=0$ and $\mathrm{dC} / \mathrm{d} t=0)$. The heavy broken line represents $a$ stable manifold (boundary) between two areas of attraction (that is, susceptibility or immunity) and the lightly broken lines represent numerical solutions of the model with varying initial conditions (that is, values of $P$ and $C$ at time $t=0$ ). Note that the high exposure to the parasite in early life (when $C$ is small) can result in susceptibility (unresponsiveness), whereas low exposure may result in the slow acquisition of resistance ${ }^{36}$. 
These factors militate against deletion analyses in which single components are removed from an experimental system, particularly when a non-natural host is involved.

The prime candidates for effective immune mechanisms against helminth organisms are the humoral and cellular components most evident during infection. The most distinctive of these features is a dramatic elevation of serum IgE antibody levels in humans $^{45}$ and rodents ${ }^{46}$ : the nematode Nippostrongylus brasiliensis raises total serum IgE levels in rodents 100 -fold in 14 days, and 10 -fold higher again on a secondary infection. This reflects a polyclonal activation, as responses to other antigens introduced before the helminth infection are also the subject of a strong $\operatorname{IgE}$ response $^{47}$. The potentiation of $\operatorname{IgE}$ (and in humans of IgG4) is mediated by a soluble cytokine, interleukin (IL)-4 (refs 48, 49), the main source of which is the Th2 helper cell subset.

Eosinophilia is equally marked in helminth infections: it has long been known that in human helminthiases more than $50 \%$ of circulating white blood cells may be eosinophil granulocytes ${ }^{50}$, in constrast to their normal level of $2-5 \%$. Similarly, in rodent infections, circulating eosinophil numbers increase 10 to 30 fold $^{51}$, a phenomenon blocked by antibodies to another Th2 lymphokine, IL-5 (ref. 52). Helminthiases also provoke proliferation of mast cells (IgE-receptor bearing cells which release pharmacologically active mediators), particularly in the mucosa of parasitized intestinal tissue ${ }^{31}$. This mastocytosis is promoted by IL-3 and other cytokines ${ }^{53}$. Lymphocytes from helminthinfected, eosinophilic patients show enhanced IL-4 and IL-5 production, again suggesting that these cytokines are directly amplified as a result of infection ${ }^{54}$.

Whether the abundance of $\mathrm{IgE}$ and eosinophils actually protect the host against helminth parasites is a matter of some contention. In human schistosomiasis, both elevated eosinophilia $^{55,56}$ and specific IgE responses ${ }^{26.28}$ correlate quantitatively with resistance to reinfection after chemotherapy, whereas in filariasis, patent microfilaraemia is associated with a depressed

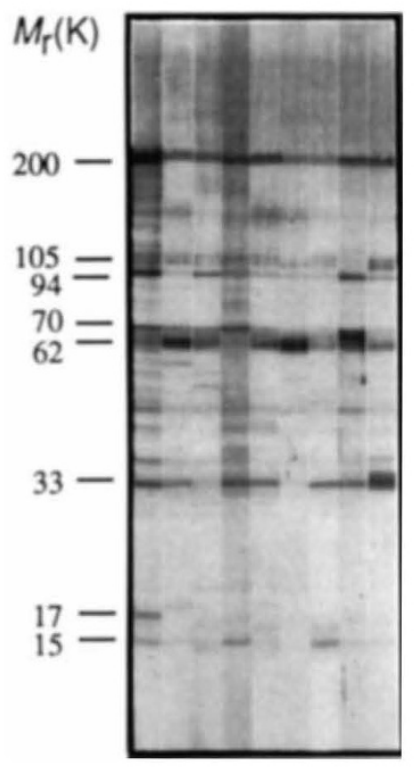

FIG. 3 Evidence that different people (of similar ages and with similar backgrounds of exposure to infection) vary in their ability to recognize and respond to particular antigens. Sera from 9 individual adult patients with high levels $\left(>100 \mathrm{mf} \mathrm{ml}^{-1}\right.$ ) of Wuchereria bancrofti microfilariae in nocturnal blood samples were used to probe a western blot of infective larval antigens taken from a closely related filarial parasite, Brugia malayi $^{24}$. No correlation was observed between the expression of a particular antibody specificity and parasitological factors such as microfilarial density, resistance to infective larvae, and age. The sizes of major components, such as myosin (200K), are indicated.
IgE response ${ }^{57}$. However, IgE-mediated hypersensitivity (due to mast cell discharge of active mediators) is linked with pathology rather than resistance in human gut trichuriasis infections ${ }^{58}$. Helminth parasites can be killed in vitro by IgE-mediated mechanisms, involving platelets, macrophages and eosinophils (Table $2)^{45}$. More evidence for a protective role of $\operatorname{IgE}$ is offered by studies on rats infected with filarial worms ${ }^{59}$ and T. spiralis ${ }^{60}$. Although protection of rats against $S$. mansoni implicates $\mathrm{IgE}^{45}$, mice depleted of $\mathrm{IgE}$ and eosinophils can be satisfactorily vaccinated $^{61}$. In conclusion, IgE probably contributes to protection against tissue helminths in humans and rats, if not always in mice.

Eosinophils certainly kill larval schistosomula in vitro, primarily by deposition of toxic granule proteins ${ }^{62}$ in synergy with reactive oxygen intermediates (ROI; for example, free superoxide and hydroxyl radicals, and hydrogen peroxide) ${ }^{63}$ (Table 2 ). In vivo, there is conflicting evidence on the ability of eosinophildepleted animals to curtail a $S$. mansoni infection ${ }^{61.64}$, but hypoeosinophilic animals have compromised immunity to migrating larvae of Strongyloides venezuelensis ${ }^{65}$ and Trichinella spiralis ${ }^{51}$. In both instances immunity to gut-living stages was unabated, demonstrating that protective mechanisms in this locale are quite distinct.

Efficient expulsion of intestinal helminths generally involves a parasite-specific induction phase which recruits a more catholic effector phase with many common elements ${ }^{31}$. During expulsion, a highly oedematous local inflammatory response occurs, characterized by mastocystosis, epithelial shedding, increased gut permeability and mucus hypersecretion ${ }^{66}$. These and other cell types may contribute inflammatory lipid mediators ${ }^{66,67}$ and damaging oxygen free radicals ${ }^{68}$. Inhibition of mastocytosis by the nematode Heligmosomoides polygyrus permits both this species, and other concurrent parasites, to remain in the gut ${ }^{69}$. Permeability changes introduce plasma effector molecules, and some of these combine with mucus in order to immobilize parasites

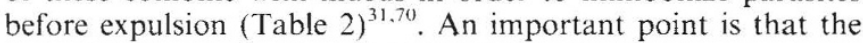
same effector mechanisms that attack intestinal worms are probably responsible for the concurrent gut pathology ${ }^{68}$. This may well be true for many tissue-dwelling parasites, and represents a major barrier to vaccine development.

In many settings, the role of lymphokine-activated macrophages appears well established. The lymphokines that activate murine macrophages are interferon- $\gamma$ (IFN- $\gamma$ ), acting in synergy with tumour necrosis factor (TNF) ${ }^{74}$, both products of the Th1 subset of helper lymphocytes. Schistosomula are killed by murine $^{71.72}$ and human ${ }^{73}$ lymphokine-activated macrophages (Table 2 ) but not by reactive oxygen intermediates produced by phagocytes stimulated through Fc receptors ${ }^{74}$. Activated murine macrophages kill schistosomula by the production of nitric oxide $^{72}$ so that, in the mouse at least, resistance is strongly associated with IFN- $\gamma$ production, which is in turn primarily generated by Thl subset cells ${ }^{75}$.

\section{Th1 and Th2 helper $T$ cells}

The two subsets of differentiated helper T cells, Th1 and Th2, are characterized by the contrasting profiles of cytokines they secrete. The Th1 products (including IFN- $\gamma$ and TNF- $\beta$ ) are inflammatory mediators and selectively activate macrophages, whereas the Th 2 cytokines (such as IL-4, IL-5 and IL-10) stimulate B-cell and eosinophil development and antibody production. Moreover, these subsets are reciprocally cross-inhibitory ${ }^{75}$, so that one cell type will gain at the expense of the other; this may explain the profoundly unbalanced Th1/Th2 ratio in most helminth infections ${ }^{76}$. The elevated eosinophilia, IgE and IgG4 expression in chronic human helminthiases suggest that Th 2 cells predominate, and indeed higher IL- 4 and lower IFN- $\gamma$ production is reported in peripheral $\mathrm{T}$ cells from heavily infected individuals ${ }^{54,77}$, and human $\mathrm{T}$-cell clones reactive to antigens from the nematode Toxocara canis show a pure Th2 profile ${ }^{78}$. However, the helper subset status in infection may not be irre- 
TABLE 2 Effector mechanisms known to act against helminths

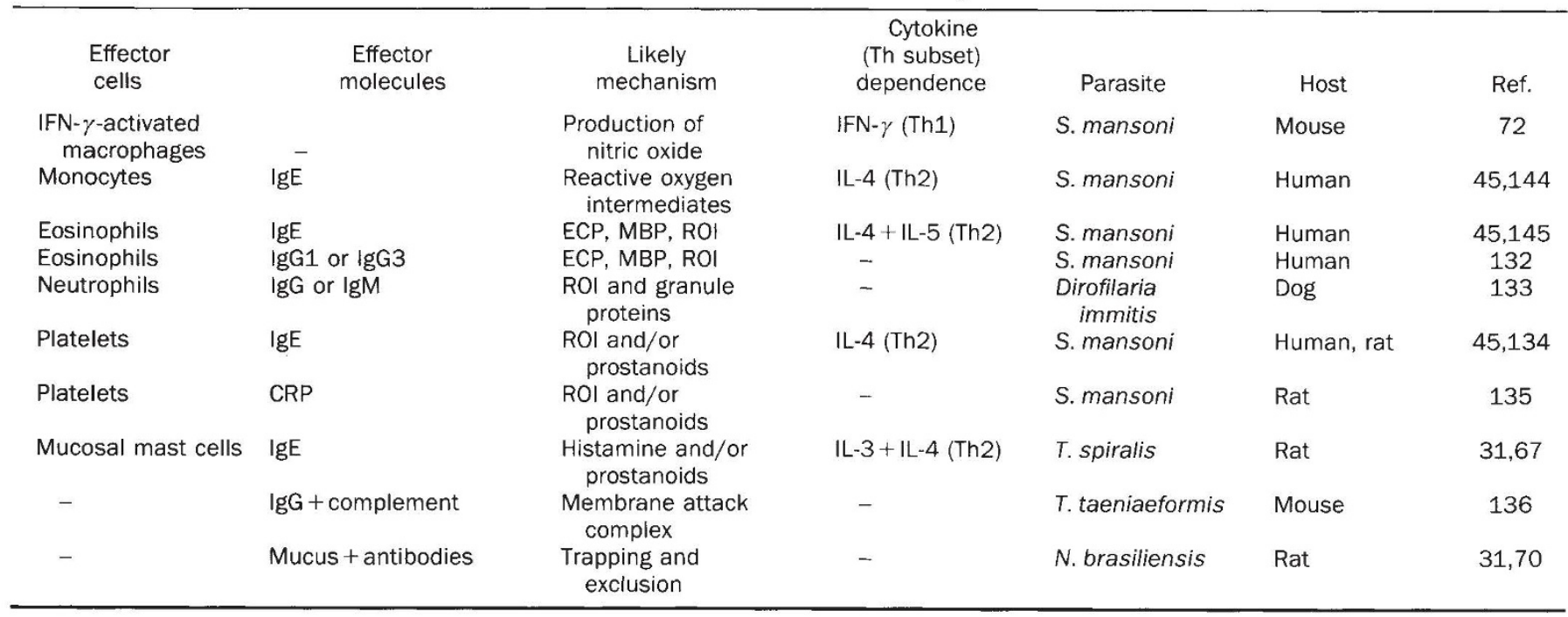

Only selected examples of each mode of helminth killing are presented for brevity. For a review of cited references, see ref. 61 . Details of S. mansoni are given in Table 1. Dirofilaria immitis is the mosquito-transmitted filarial nematode of dogs, heartworm. Nippostrongylus brasiliensis is a strongylid nematode in the gut of rodents which follows a hookworm-like life cycle. Taenia taeniaeformis is a cestode found in the adult stage in the cat intestine, forming cysts in intermediate rodent hosts on ingestion of eggs. Abbreviations: ECP, eosinophil cationic protein; MBP, major basic protein; ROI, reactive oxygen intermediates (hydrogen peroxide, hydroxyl radicals, hypohalous acids, singlet oxygen and superoxide); prostanoids include hydroxyeicosatetraenoic acids, leukotrienes, prostacyclin, prostaglandins and thromboxane.

vocable; in murine schistosomiasis, an early Thl-line response is superseded by a stronger Th2 response after egg production ${ }^{79}$ or following repeated immunization with attenuated larvae ${ }^{80}$.

At issue is whether Thl cells are generally protective against helminth parasites. Although the singly immunized mouse model for schistosomiasis suggests that Thl is the protective cell type for larvicidal responses ${ }^{79}$, evidence from infections with the whipworm, Trichuris muris, argues cogently against drawing a general conclusion of this nature. In this system, susceptible strains of inbred mice show Th1 activation, measured by high IFN- $\gamma$ production, whereas resistant mice produce little IFN$\gamma$ and elevated IL-5, symptomatic of a strong Th2 response ${ }^{81}$. Moreover, anti-larval (concomitant) immunity to the mouse nematode Heligmosomoides polygyrus is ablated by anti-IL-4 treatment ${ }^{82}$, and can be passively transferred by IgG1 antibodies $^{83}$, which are potentiated by IL-4 (ref. 48). However, in T. spiralis, expression of Th1-mediated properties, such as high IFN- $\gamma$ and serum IgG2a, have been associated with fast expulsion of the gastrointestinal adult worms ${ }^{84}$, confirming that the critical T-cell population may differ in each parasite combination and in each tissue site. Thus, there is as yet no evidence for a common anti-helminth immune mechanism; as parasites have evolved multifarious ways of evading appropriate steps in various immune cascades, generalizations must await data from a sufficiently broad range of host-parasite combinations. In this context, patterns of T-cell cytokine production in human helminth infection ${ }^{54,77,85}$ will illuminate both the role of T-cell subsets in parasitic disease, and more generally establish the extent to which the human T-cell response conforms to the highly polarized $T h 1 / 2$ distinction found in mice ${ }^{86,87}$.

\section{Parasite defence strategies}

Infectious organisms have evolved a diverse array of specific and general adaptations to evade the host immune system ${ }^{88,89}$. The defence strategies used by helminths ${ }^{89,90}$, constrained by replication rate and extracellular locale, can be divided into three classes: avoiding initial induction of damaging immune responses; compromising selected arms of the immune system; and disabling the short-range offensives mounted by various effector mechanisms. (A summary of helminth molecules involved in these defences is given in Table 3.)
Some devices exploited by helminths to block induction have been well described: molecular mimicry and uptake of host antigens ${ }^{29,91}$ are two means by which a helminth may confer 'self' status upon itself, whereas secretion of the hapten phosphorylcholine may be a diversionary tactic ${ }^{5}$. Schistosomes absorb host $\mathrm{MHC}^{91}$, conceivably as defence against natural killer (NK) cells (which react to aberrent expression of MHC), but also take up decay-accelerating factor (conferring protection from complement-mediated attack ${ }^{92}$ ), contrapsin (an antithrombotic serum serine protease inhibitor ${ }^{93}$ ), and low-density lipoproteins (possibly causing the progressive loss of antibody binding sites with maturation ${ }^{94}$ ). In these instances, uptake of host molecules is quintessentially parasitic, to subvert host functions to the well-being of the parasite.

Because these strategies offer only limited scope for expression of products necessary for the parasitic mode of life, more directed means of regulating immunity are required. The extracellular niche of helminths makes the immune system dependent upon the exogenous pathway for antigen presentation. However, macrophages from schistosome- ${ }^{95}$ and H. polygyrus ${ }^{96}$-infected mice are incompetent antigen presenters. Possibly the quantity of polysaccharides and glycoconjugates produced may interfere with antigen processing ${ }^{97}$ : secretions containing phosphorylcholine from nematodes may act to inhibit activation ${ }^{98}$. Antigen processing generally requires cysteinyl and aspartyl proteases such as capthepsins $\mathrm{B}$ and $\mathrm{D}^{99}$. Filarial worms release a cystatinlike molecule ${ }^{100}$ which may block cathepsin $\mathrm{B}$, whereas antigen processing in B cells can be blocked by an aspartic protease inhibitor from Ascaris lumbricoides ${ }^{101}$. Other protease inhibitors act in the extracellular milieu: taeniaestatin, a $19.5 \mathrm{~K}$ serine protease inhibitor from metacestode larvae of Taenia taeniaeformis, inhibits chemotaxis by neutrophils, as well as T-cell proliferation and production of IL-2 (ref. 102). Interference with signalling and antigen presentation may not only block a response, but also induce a state of immunological unresponsiveness, or tolerance $e^{103}$, in which there can be long-term assimilation of parasites into their host environment. The dynamics of a chronic infection and persistent antigen would favour maintenance of the tolerant state sto,104. $^{3}$.

- An equally effective strategy may be to neutralize only those components of the immune system that pose a real danger. Para- 
Parasite

Immunoglobulin-cleaving proteases

\section{Dirofilaria immitis}

Fasciola hepatica

Schistosoma mansoni

Protease inhibitors

Echinococcus granulosus

Onchocerca volvulus

Taenia-taeniaformis

\section{Antioxidants}

Brugia pahangi

Onchocerca volvulus

Schistosoma japonicum

Schistosomamansoni

\section{Other factors}

Brugia malayi

Heligmosomoides polygyrus

Nippostrongylusbrasiliensis

Schistosoma mansoni

Taenia solium

Taenia taeniaeformis

Taenia taeniaeformis
Product

Comments

Ref.

On parasite surface

Surface

107

106

105

\section{$12 \mathrm{~K} \mathrm{Ag} \mathrm{B}$}

Cystatin

Taeniaestatin

Secreted into cyst fluid

109

On parasite surface

$\mathrm{IL}-2 /$ chemotaxis inhibitor

100

102

GPX

SOD

GST

GST

Surface/secreted

Secreted

122

On parasite surface

On parasite surface

123

125

Prostaglandin E2 Immunosuppressant PAF hydrolase

Immunosuppressant

Paramyosin

Sulphated proteoglycan

Prostaglandin E2
Mf secreted

111

Adult worm associated

96

Secreted

Secreted

C1-binding; secreted

C3-consuming; secreted

Larval secretions
110

138

139

108

112

Abbreviations: SOD, superoxide dismutase; PAF, platelet-activating factor; GPX, glutathione peroxidase; GST, glutathione-S-transferase; C1 and $\mathrm{C} 3$, first and third components of complement; IL-2, interleukin-2. Details on 0 . volvulus and S. mansoni are given in Table 1 , and on D. immitis, $N$. brasiliensis and T. taeniaeformis in Table 2. Brugia malayi and B. pahangi are filarial nematodes closely related to W. bancrofti (Table 1). Echinococcus granulosus is a cestode of dogs, transmitted through eggs found in soil, which causes hydatid cysts in humans. Fasciola hepatica is the liver fluke, parasitizing sheep and cattle and transmitted through an intermediate snail host. Heligmosomoides polygyrus is a gastrointestinal nematode of mice, with a direct faecal-oral cycle. Schistosoma japonicum is a blood fluke with a similar life cycle to that of S. mansoni. Taenia solium is the tapeworm acquired by humans from cysts in infected pork; the same species causes cysticercosis if eggs are ingested.

sites can directly or indirectly block the effects of antibody with surface or secreted proteases capable of degrading host immunoglobulin molecules ${ }^{105-107}$, while complement function is compromised in tapeworm cysts by highly sulphated proteoglycans which activate complement in the fluid phase ${ }^{108}$. Host inflammatory reactions are also interrupted by helminths. The cestode Echinococcus granulosus secretes an elastase inhibitor which blocks neutrophil attraction by C5a or platelet-activating factor $(\mathrm{PAF})^{109}$. PAF may be neutralized directly through cleavage by secreted acetylhydrolases, as documented for N. brasiliensis $^{110}$. Filarial $^{111}$ and taeniaed ${ }^{112}$ parasites use endogenous and exogenous arachidonic acid to produce and release prostanoids (prostacyclin and $\mathrm{PGE}_{2}$ ), which in addition to these anti-inflammatory properties may also inhibit $\mathrm{T}$-cell proliferation.

Selective inhibition of T-cell subsets is evidenced in filariasis in which proliferative $\mathrm{T}$ cells show antigen-specific anergy, but antibody responses remain intact ${ }^{85,113}$; this has been interpreted as Th1-subset anergy ${ }^{114}$. High levels of IgE and IgG4 are produced during helminth infections. Co-expression of these two isotypes may be beneficial as IgG4 can block IgE-mediated allergic responses ${ }^{115}$. Protective mechanisms may also be modulated by the IgG4: IgE ratio, which tends to be high in heavily infected individuals in schistosomiasis ${ }^{26}$ and filariasis ${ }^{57}$. Antibodies of the IgM and IgG2 isotypes (directed against carbohydrate determinants) also block responses to schistosomula by granulocytes which are guided by antibodies of other isotypes in the antibody-dependent cell-mediated cytotoxicity reaction ${ }^{116}$. The presence of these blocking antibodies is correlated with susceptibility to reinfection following chemotherapy of a human population, whereas expression of IgG1 and IgG3 antibodies to the same epitopes correlate with resistance.

- The third layer of the helminth strategy involves a set of short-term defences to ward off the many forms of intense attack which may be mounted by the host immune system. Physical effects include the thickening of the schistosome tegument during maturation ${ }^{117}$, and the corresponding inaccessibility of the nem- atode hypodermal plasma membrane beneath a thick extracellular cuticle. The increasing invulnerability of maturing helminths may contribute towards the operation of concomitant immunity. Many nematodes have a loose surface coat which can be readily sloughed off under immune attack ${ }^{118}$, and Fasciola juvenile flukes show a similar rapid turnover of surface glycocalyx ${ }^{119}$.

To counteract the oxidative burst of activated host leukocytes, helminths express surface or secreted antioxidant enzymes ${ }^{120}$ such as superoxide dismutase ${ }^{121}$, glutathione peroxidase $(G P X)^{122}$ and glutathione $S$-transferase $(G S T)^{123,124}$. GST is localized in the external tegument of schistosomes ${ }^{125}$, and successfully immunizes rats against challenge $\mathrm{e}^{124}$. The major role of these enzymes may be to protect surface membranes against peroxidation; it is notable that GST/GPX expression, and parasite resistance to oxidants, each progressively rise through the schistosome life cycle ${ }^{126}$.

\section{Discussion}

Successful helminth parasites combine specific molecular strategies to combat the threat of immediate immune attack, with quantitative and dynamic properties which permit long-term establishment within an individual host (by tolerance induction, for example) and within the host population (such as by overdispersion in 'wormy' individuals). Recent molecular and immunological advances have developed new insights and opportunities for the analysis of macroparasite transmission and immunity in human communities. There is a growing emphasis in epidemiological studies on the dynamic interaction between parasite populations and the immune system, on delineating temporal changes in parasite levels and immunological responses, and on recording variability between human hosts. In human filariasis, for example, the rate of increase in infection can now be measured with assays for parasite antigen circulating in the bloodstream ${ }^{25}$, and the host response can be monitored more precisely by measuring antibodies of a single isotype $\mathrm{e}^{127}$ or to a single parasite antigen ${ }^{128}$.

The structural and developmental sophistication of macropar- 
asites is clearly reflected in the multiplicity of pathways by which parasites interact with the host immune system. It is often argued that the Th2 subset (and, in particular, IgE) has evolved to help combat helminth infection. If so, it may also be that extant helminth parasites have evolved mechanisms that allow them to counteract Th2 responses. The success of these parasites (as indicated by their high prevalences in the developing world) suggests a very dynamic evolution where continued selection enables the parasite to evade or modulate the immunological attack in at least some fraction of the host population (the 'wormy' individuals).

Theoretical studies of parasite mediated modulation of immune responses and the dynamic interaction betwen Th1 and Th2 responses to helminth infections have generated new hypotheses to explain heterogeneity and predisposition based on the induction of specific immunological non-responsiveness (tolerance or anergy) to parasite antigens through high exposure very early in life ${ }^{36}$. These ideas require testing in areas of endemic infection by immuno-epidemiological studies of infants and children (inc ling those in whom neonatal tolerance may have resulted from naternal infection $^{35}$ ), and of laboratory systems. Key to these 3 ypotheses are the influence of the parasite in disrupting the regulation of helper (responsive) and suppressor (unresponsive) activities in a multicomponent immune response.

Heterogeneity in parasite burdens, where a small fraction of the community harbours the majority of the parasites, also has implications for parasite evolution. If those predisposed to heavy infection are less immunologically competent to resist repeated infection (due to genetic or nutritional factors), they therefore provide a refugium for the evolution of new variants via sexual reproduction. Transmission of these variants to the majority of immunocompetent hosts will select for viable organisms with enhanced ability to modulate or evade immunological responses.

The many opportunities presented by advances in molecular biology for the study of immunity to helminths are paralleled by the dangers of an ever-expanding descriptive literature ${ }^{129}$. The population ecology of the immune system is undoubtedly a very nonlinear world: future research will need to emphasize the measurement and quantification of the rate parameters that control humoral and cellular responses to parasite antigens, and the functional dependencies between parasite and immune system variables that determine the dynamics of the interaction ${ }^{130}$. The Th1/Th2 balance or imbalance is a good example of this need. Simple theory points to two attractors in this dynamic interaction of enhanced or suppressed responsiveness (Fig. $2 d$ ), separated by an unstable boundary where small quantitative changes in particular parameters of the immune system can switch the host from anergy and unresponsiveness to immunity. The need for the new molecular tools is beginning to be appreciated by the field epidemiologist, but perhaps immunologists have not always appreciated the need for field and mathematical approaches.

To understand patterns of infection, reinfection and response, molecular techniques must be integrated into long-term studies of exposure and infection. Future field research will then be able to monitor the population dynamics of immunological responses, as well as to conduct longitudinal studies in individual patients that chart changes in particular modes of the immune response in relation to infection and the slow acquisition of immunity in the majority of those exposed ${ }^{116}$. To help interpret field observations, laboratory studies are required with animal models that centre on the dynamics of repeated exposure as the host ages, and which examine long-term presentation of antigens, as opposed to the short exposure to abrupt pulses of parasites or defined antigens upon which current models of immune responsiveness have been built. The marked heterogeneity in worm loads within human communities, and the evidence for predisposition to heavy or light infection is a help not a hindrance in such research. It is becoming increasingly apparent that heterogeneity not only reflects differences in exposure, but also host genetic factors involved in epitope selection and immune effector function. Work on laboratory rodent/helminth systems suggests that there may be host genes that determine predisposition $^{37}$, and the association between HLA genotype and infection intensity is now being actively analysed.

The all-too-apparent complexity of the interaction between helminth parasites and the human immune system (our appreciation of which has been magnified by new molecular and immunological tools) may deter rather than encourage the choice of these systems as models for the study of infection and immunity. This is a crucial challenge, however, because understanding how these organisms persist in the host, despite a diversity of specific and nonspecific immunological defences directed at them, is likely to provide essential new insights, not only into the functioning of the human immune system, but also into the design of vaccines and therapies to combat antigenically diverse infectious agents.

The authors are at the Wellcome Research Centre for Parasitic Infections, Departments of Biology (R.M.M., D.A.P.B. and R.M.A.) and Biochemistry (M.E.S. and D.F.S.), Imperial College of Science, Technology and Medicine, Prince Consort Road, London SW7 2BB, UK.

1. Warren, K. S. \& Mahmoud, A. A. F. Tropical and Geographic Medicine (McGraw-Hill, New York, 1984).

2. Anderson, R. M. \& May, R. M. Nature 280, 361-367 (1979)

3. Anderson, R. M. \& May, R. M. Adv, Parasit. 24, 1-101 (1985)

4. Butterworth, A. E. Fulford, A. J. C., Dunne, D. W., Ouma, J. H. \& Sturrock, R. F. Phil. Trans. R. Soc. B 321, 495-511 (1988).

5. Maizels, R. M. \& Selkirk, M. E. in The Biology of Parasitism (eds Englund, P. T. \& Sher, A.) 285-308 (Liss, New York, 1988).

6. Anderson, R. M. Trans. R. Soc. Trop. Med. Hyg. 80, 686-696 (1986).

7. Schad, G. A. \& Anderson, R. M. Science 228, 1537-1540 (1985).

8. Keymer, A. \& Pagel, M. in Hookworm Disease: Current Status and New Directions (eds Schad, G. A. \& Warren, K. S.) 177-209 (Tayior and Francis, London, 1990).

9. Warren, K. S. in Bailliere's Clinical Tropical Medicine and Communicable Diseases (ed. Mahmoud, A. A. F.) 301-313 (Balliere, London, 1987).

10. Nokes, C., Grantham-McGregor, S. M., Sawyer, A. W., Cooper, E. S. \& Bundy, D. A. P. Proc. R. Soc. B 247, 77-81 (1992).

11. Ottesen, E. A. Rev. Infect. Dis, 7, 796-801 (1985)

12. Nadler, S. A. Parasit. Today 3, 154-155 (1987).

13. Anderson, R. M. \& May, R. M. Infectious Diseases of Humans. Dynamics and Control $1-$ 757 (Oxford Univ. Press, Oxford, 1991)

14. Anderson. R. M. \& Medley, G. F. Parasitology 90, 629-660 (1985).

15. Anderson, R. M. \& May, R. M. Nature 297, 557-563 (1982).

16. Guyatt, H. L., Bundy, D. A. P., Medley, G. F. \& Grenfell, B. T. Parasitology 101, 139-143 (1990).

17. Butterworth, A. E. et al. Trans. R. Soc. Trop. Med. Hyg. 79, 393-408 (1985).

18. Bundy, D. A. P., Grenfell, B. T. \& Rajagopalan, P. K. in Immunoparasit. Today (eds Ash, C. \& Gallagher, R. B.) A71-A75 (Elsevier, Cambridge, 1991).

19. Wilkins, H. A., Blumenthal, U. J., Hagan, P., Hayes, R. J. \& Tulloch, S. Trans. R. Soc. Trop. Med. Hyg. 81, 29-35 (1987)

20. Chandiwana, K. K., Woolhouse, M. E. J. \& Bradley, M. Parasitology 102, 73-83 (1991).

21. Wong, M. S. Trans. R. Soc. Trop. Med. Hyg. 85, $89-91$ (1990).

22. Anderson, R. M. \& May, R. M. Nature 315, 493-496 (1985)

23. Woolhouse, M. E. J., Taylor, P., Matanhire, D. \& Chandiwana, S. K. Nature 351, 757-759 (1991).

24. Day, K. P., Gregory, W. F. \& Maizels, R. M. Parasite Immun. 13, 277-290 (1991).

25. Day, K. P., Grenfell, B., Spark, R., Kazura, J. W. \& Alpers, M. P. Am. J. Trop. Med,. Hyg. 44, 518-527 (1991).

26. Hagan, P., Blumenthal, U. J., Dunn, D., Simpson, A. J. G. \& Wilkins, H. A. Nature 349, 243-245 (1991).

27. Bundy, D. A. P., Lillywhite, J. E., Didier, J. M., Simmons, I. \& Bianco, A. E. Parasite Immun 13, 629-638 (1991).

28. Dunne, D. W. et al. Eur. J. Immun. 22, 1483-1494 (1992).

29. Smithers, S. R. \& Terry, R. J. Ann. N.Y. Acad. Sci. 160, 826 (1969)

30. Mitchell, G. F. Immunology 38, 209-223 (1979)

31. Miller, H. R. P. Vet. Immun. Immunopath. 6, 167-259 (1984)

32. Wilson, R. A. Parasit. Today 6, 354-358 (1990).

33. Haswell-Elkins, M. R., Elkins, D. B. \& Anderson, R. M. Parasitology 95, 323-328 (1987).

34. Tingley, G. A. et al. Trans. R. Soc. Trop. Med. Hyg. 82, 448-452 (1988).

35. Lammie, P. J., Hitch, W. L., Walker Allen, E. M., Hightower, W. \& Eberhard, M. L. Lancet 337, 1005-1006 (1991).

36. Schweitzer, N. \& Anderson, R. Proc. R. Soc. B 247, 107-112 (1992).

37. Wakelin, D, in Genetics of Resistance to Bacterial and Parasitic Infection (eds Wakelin D. M. \& Blackwell, J. M. 153-232 (Taylor and Francis, London, 1988).

38. Bundy, D. A. P. Parasitology 95, 623-635 (1987).

39. Bundy, D. A. P. \& Medley, G. F. Parasitology 104, 105-119 (1992).

40. Kennedy, M. W. Parasit. Today 5, 316-324 (1989).

41. Hirayama, K. et al. Nature 327, 426-430 (1987).

42. Wassom, D. L., Wakelin, D., Brooks, B. O., Krco, C. J. \& David, C. S. Immunology 51, 625$631(1984)$

43. Needham, C. S. et al. Parasitology 105, 275-283 (1992)

44. Needham, C. S. \& Lillywhite, J. E. Trans. R. Soc. Trop. Med. Hyg. (in the press)

45. Capron, A. \& Dessaint, J. P. A. Rev. Immun. 3, 455-476 (1985).

46. Ogilvie, B. M., Smithers, S. R. \& Terry, R. J. Nature 209, 1221-1223 (1966).

47. Jarrett, E. E. E. \& Miller, H. R. P. Prog. Allerg. 31, 178-233 (1982).

48. Finkelman, F. D. et al. A. Rev. Immun. 8, 303-333 (1990).

49. Lundgren, M. et al. Eur. J. Immun. 19, 1311-1315 (1989).

50. Brown, T. R. J. exp. Med. 3, 315-347 (1898). 
51. Grove. D. I., Mahmoud, A. A. F. \& Warren, K. S. J. exp. Med. 145, 755-759 (1977).

52. Coffman, R. L., Seymour, B. W. P., Hudak, S., Jackson, J. \& Rennick, D. Science 245, 308 310 (1989).

53. Madden, K. B. et al. J. Immun. 147, 1387-1391 (1991).

54. Mahanty, S., Abrams, J. S., King, C. L., Limaye, A. P. \& Nutman, T. B. J. Immun. 148, 3567-3571 (1992)

55. Sturrock, R. F. et al. Trans. R. Soc. Trop. Med. Hyg. 77, 363-371 (1983).

56. Hagan, P., Wilkins, H. A., Blumenthal, U. J., Hayes, R. J. \& Greenwood, B. M. Parasite Immun. 7, 625-632 (1985).

57. Kurniawan, A. et al. J. Immun. 150, 3941-3950 (1993).

58. Cooper, E. S. et al. Lancet 338, 1104-1107 (1991).

59. Gusmäo, R. de, Stanley, A. M. \& Ottesen, E. A. Expl Parasit. 52, 147-159 (1981).

60. Dessein, A. J., Parker, W. L., James, S. L. \& David, J. R. J. exp. Med. 153, 423-436 (1981).

61. Sher, A., Coffman, R. L., Hieny, S. \& Cheever, A. W. J. Immun. 145, 3911-3916 (1990).

62. Butterworth, A. E. Adv. Parasit. 23, 143-235 (1984).

63. Yazdanbakhsh, M., Tai, P.-C., Spry, C. J. F., Gleich, G. J. \& Roos, D. J. Immun. 138, 34433447 (1987).

64. Mahmoud, A. A. F., Warren, K. S. \& Peters, P. A. J. exp. Med. 142, 805-813 (1975).

65. Korenaga, M. et at. Immunology 72, 502-507 (1991).

66. Moqbel, R. \& MacDonald, A. J. in Parasites: Immunity and Pathology. The Consequences of Parasitic infection in Mammals (eds Behnke, J. M.) 249-282 (Taylor and Francis, London, 1990)

67. Moqbel, R. et al. Immunology 60, 425-430 (1987).

68. Smith, N. C. Parasit. Res. 75, 423-438 (1989).

69. Dehlawi, M. S., Wakelin, D. \& Behnke, J. M. Parasite Immun. 9, 187-194 (1987).

70. Miller, H. R. P., Huntley, J. F. \& Wallace, G. R. Immunology 44, 419-429 (1981).

71. Esparza, I., Männel Ruppel, A., Falk, W. \& Krammer, P. H. J. exp. Med. 166, 589-594 (1987).

72. James, S. L. \& Glaven, J. J. Immun. 143, 4208-4212 (1989).

73. Cottrell, B. J., Pye, C., Glauert, A. M. \& Butterworth, A. E. J. Cell Sci. 94, 733-741 (1989).

74. Scott, P., James, S. \& Sher, A. Eur. J. Immun. 15, 553-558 (1985)

75. Mosmann, T. R. \& Coffman, R. L. A. Rev. Immun. 9, 145-173 (1989)

76. Sher, A. F. \& Coffman, R. L. A. Rev. Immun. 10. 385-409 (1992).

77. Zwingenberger, K., Hohmann, A., Cardoso de Brito, M. \& Ritter. M. Scand. J. Immun. 34, 243-251 (1991).

78. Del Prete, G. et al. J. clin. invest. 88, 346-350 (1991).

79. Pearce, E. J., Caspar, P., Grzych, J.-M., Lewis, F. A. \& Sher, A. J. exp. Med. 173, 159-166 (1991).

80. Caulada-Benedetti, Z., Al-Zamel, F., Sher, A. \& James, S. J. Immun. 146, 1655-1660 (1991).

81. Else, K. J. \& Grencis, R. K. Immunology 72, 508-513 (1991).

82. Urban, J. F. Jr. Katona, I. M., Paul, W. E. \& Finkelman, F. D. Proc. natn. Acad. Sci. U.S.A. 88, 5513-5517 (1991).

83. Pritchard, D. I., Williams, D. J. L., Behnke, J. M. \& Lee, T. D. G. Immunology 49, 353-365 (1983).

84. Pond, L., Wassom, D. L, \& Hayes, C. E. J. Immun. 143, 4232-4237 (1989).

85. Yazdanbakhsh, M. et al. J. infect. Dis. 167, 925-931 (1993).

86. Romagnani, S. Immun. Today 12, 256-257 (1991).

87. Wierenga, E. A. et al. J. immun. 147, 2942-2949 (1991).

88. Gooding, L. R. Cell 71, 5-7 (1992).

88. Gooding, L. R. Cell 71, 5-7 (1992).

Dessaint, J.P. \& Capron, A. R. in immunology and Molecular Biology of Paras
3rd edn (ed. Warren, K. S.) 87-99 (Blackwell Scientific, Boston, 1993).

90. Behnke, J. M., Barnard, C. J. \& Wakelin, D. Int. J. Parasit. 22, 861-907 (1992).

91. Sher, A. \& Moser, G. Am. J. Path. 102, 121-126 (1981).

92. Pearce, E. J., Hall, B. F. \& Sher, A. J. Immun. 144, 2751-2756 (1990).

93. Modha, J., Parikh, V., Gauldie, J. \& Doenhoff, M. J. Parasitology 96, 99-109 (1988).

94. Chiang, C.-P. \& Caulfield, J. P. Am. J. Path. 134, 1007-1018 (1989).

95. Stadecker, M. J., Kamisato, J. K. \& Chikunguwo, S. M. J. Immun. 145, 2697-2700 (1990).

96. Pritchard, D. I., Ali, N. M. H. \& Behnke, J. M. Immunology 51, 633-642 (1984)

97. Leyva-Cobian, F. \& Unanue, E. R. J. Immun. 141, 1445-1450 (1988).

98. Lal, R. B., Kumaraswami, V., Steel, C. \& Nutman, T. B. Am. J. Trop. Med. Hyg. 42, 56-64 (1990).
99. Diment, S. J. Immun. 145, 417-422 (1990).

100. Lustigman, S., Brotman, B., Huima, T. \& Prince, A. M. Molec. Biochem. Parasit. 45, 6576 (1991).

101. Bennett, K. et al. Eur. J. Immun. 22, 1519-1524 (1992).

102. Leid, R. W., Suquet, C. M., Bouwer, H. G. A. \& Hinrichs, D. J. J. Immun. 137, 2700-2702 (1986).

103. Schwartz, R. H. Science 248, 1349-1356 (1990).

104. Ramsdell, F. \& Fowlkes, B. J. Science 257, 1130-1134 (1992).

105. Auriault, C., Ouaissi, M. A., Torpier, G., Eisen, H. \& Capron, A. Parasite Immun. 3, 33-41 (1981).

106. Chapman, C. B. \& Mitchell, G. F. Vet. Parasit. 11, 165-178 (1982).

107. Tamashiro, W. K., Rao, M. \& Scott, A. L. J. Parasit. 73, 149-154 (1987)

108. Hammerberg, B. \& Williams, J. F. J. Immun. 120, 1033-1037 (1978).

109. Shepherd, J. C., Aitken, A. \& McManus, D. P. Molec. Biochem. Parasit. 44, 81-90 (1991)

110. Blackburn, C. C. \& Selkirk, M. E. Immunotogy 75, 41-46 (1992).

111. Liu, L. X., Serhan, C. N. \& Weller, P. F. J. exp. Med. 172, 993-996 (1990).

112. Leid, R. W. \& McConnell, L. A. Prostagland. Leukotri. Med. 11, 317-323 (1983)

113. Nutman, T. B., Kumaraswami, V. \& Ottesen, E. A. J. clin. Invest. 79, 1516-1523 (1987).

114. Maizels, R. M. \& Lawrence, R. A. Parasit. Today 7, 271-276 (1991).

115. Ottesen, E. A., Kumaraswami, V., Paranjape, R., Poindexter, R. W. \& Tripathy, S. P. J. Immun. 127, 2014-2020 (1981)

116. Butterworth, A. E. et al. Parasitology 94, 281-300 (1987).

117. Dessein, A. et al. Parasitology 82, 357-374 (1981)

118. Blaxter, M. L., Page, A. P., Rudin, W. \& Maizels, R. M. Parasit. Today 8, 243-247 (1992).

119. Hanna, R. E. B. Expl Parasit. 50, 103-114 (1980)

120. Callahan, H. L., Crouch, R. K. \& James, E. R. Parasit. Today 4, 218-225 (1988)

121. Simurda, M. C., van Keulen, H., Rekosh, D. \& LoVerde, P. T. Expl Parasit. 67, 73-84 (1988).

122. Cookson, E., Blaxter, M. L. \& Selkirk, M. E. Proc. natn. Acad. Sci. U.S.A. 89, 5837-5841 (1992)

123. Smith, D. B. et al. Proc. natn. Acad. Sci. U.S.A. 83, 8703-8707 (1986)

124. Balloul, J. M. et al. Nature 326, 149-153 (1987).

125. Taylor, J. B. et al. EMBO J. 7, 456-472 (1988)

126. Nare, B., Smith, J. M. \& Prichard, R. K. Expl Parasit. 70, 389-397 (1990)

127. Kwan-Lim, G.-E., Forsyth, K. P. \& Maizeis, R. M. J. Immun. 145, 4298-4305 (1990).

128. Dissanayake, S., Xu, M. \& Piessens, W. F. Molec. Biochem. Parasit. 56, 269-278 (1992).

129. Maddox, J. Nature $\mathbf{3 6 3}, 13$ (1993).

130. Anderson, R. M. J. Anim. Ecol. 60, 1-50 (1991)

131. Muller, R. Worms and Disease, a Manual of Medical Helminthology (Heinemann Medical, London, 1975).

132. Muller, R. in Immunology and Molecular Biology of Parasitic Infections 3rd edn (ed. Warren, K. S.) 567-598 (Blackwell Scientific, Boston, 1993)

133. Joseph, M., Capron, A., Butterworth, A. E., Sturrock, R. F. \& Houba, V. Clin. Exp. Immunol. 33, 48-56 (1978).

134. Capron, M. et al. J. Immun. 132, 462-468 (1984)

135. Khalife, J. et al. J. Immun. 142, $4422-4427$ (1989)

136. Rzepczyk, C. M. \& Bishop, C. J. Parasite Immun. 6, 443-457 (1984).

137. Joseph, M., Auriault, C., Capron, A., Vorng, H. \& Viens, P. Nature 303, 810-812 (1983).

138. Bout, D. et al. Science 231, 153-156 (1986).

139. Mitchell, G. F. Adv. Immun. 28, 451-511 (1979).

140. Henkle, K. J., Liebau, E., Müller, S., Bergmann, B. \& Walter, R. D. Infect. Immun. 59, 2063-2069 (1991).

141. Mazingue, C. et al. int. Arch. Allerg. appl. Immun. 83, 12-18 (1987).

142. Laclette, J. P. et al. J. Immun. 148, 124-128 (1992)

143. Webber, R. H. S. E. Asian J. trop. Med. Pub. Hith 27, 59-85 (1975).

144. Elkins, D. B., Haswell-Elkins, M. \& Anderson, R. M. Trans. R. Soc. Trop. Med. Hyg. 80, 774-792 (1986)

145. Bundy, D. A. P. Phil. Trans. R. Soc. Lond. B 321, 405-420 (1988).

ACKNOWLEDGEMENTS. We thank the Welicome Trust for support through the Welicome Research Centre for Parasitic Infections at Imperial College. 